\title{
A expresión lingüística do significado de "causalidade"
}

\section{Manuel Mosteiro Louzao}

UNED - A Coruña

1. A relación lóxica de causalidade, segundo a cal todo efecto $(q)$ está precedido no tempo dunha causa $(p)$ que o xera, maniféstase lingüisticamente de diferentes maneiras, dependendo, entre outros factores, da natureza da propia causa (real ou hipotética), do nexo empregado ou da posición das cláusulas. Estas, que mediante o principio de recursividade poden dominar á súa vez outras, ó se poñeren en relación, dan lugar a diferentes clases de oracións' que presentan varios puntos en común. Correspóndense, en senso amplo, coas tradicionalmente denominadas "adverbiais impropias", salvo as comparativas².

2. O criterio taxonómico aplicado a estas oracións adverbiais non é unánime entre os lingüistas. Así, Sánchez Márquez (1982: 232-33) inclúeas todas entre as circunstanciais (que el diferencia das adverbiais), pero se tivese que "subagrupalas", quedaríase coa clasificación de Balderrama-Sibemhart, quen distribúe todas as circunstanciais en dous grupos, descritivas e causativas, diferenciando dentro das segundas as causais, condicionais, concesivas, finais e consecutivas.

Aquí referímonos só a estructuras oracionais, aínda que o significado de 'causa' se pode expresar tamén mediante frases ou sintagmas preposicionais introducidos polos enlaces por, de, con ou ante:

(1) Fíxoo por amor

(2) Tremía de medo

(3) Foise degradando co uso

(4) Ante tanta presión, non tivo outra saída que demitir

Outras veces, no sitio da preposición empréganse locucións, como a/por causa de, por motivo de, por culpa de, gracias a, debido a, a forza de, etc., case todas gramaticalizadas polo uso.

Tamén rexistramos na lingua exemplos en que o sentido final, condicional ou concesivo está expresado por grupos preposicionais en función adverbial:

(5) Acompañouno para a súa seguridade

(6) No teu caso, eu iríame

(7) Para a súa idade, anda ben lixeiro

2 E aínda dalgunhas comparativas, como as de igualdade, pódese dicir que gardan certo parentesco (histórico, formal e semántico) coas consecutivas de intensidade, segundo advirte Narbona, para quen "la 'consecuencia' derivaría de una comparación implícita con un elemento -ideal y no definido ni explícito- al que se le asignaría o atribuiría la base de la comparación como rasgo o característica propia" (1990: 78). Para máis información, poden consultarse este mesmo autor (1978) e Martínez (1994a: 161-172). 
Tamén Alarcos et alii (1981: 120-24), ó clasificaren as oracións en función de aditamento, distinguen dous grandes grupos: as subordinadas circunstanciais (lugar, tempo e modo) e as de causalidade (en que inclúen as cinco clases de oracións mencionadas anteriormente). Del Campo (1998: 203-27) adica o capítulo oitavo do seu traballo sobre as construccións causais en español ${ }^{3}$ a estudiar as afinidades e diverxencias formais, funcionais e semánticas expresadas por estas últimas, que constitúen, así mesmo, un grupo entre os cinco en que Tekavčic (1972: 615-616) divide as "proposicións-complemento" do italiano. Tamén Tesnière (1982: 588-606) as caracteriza en francés a partir dos distintos tipos de 'causa' que expresan.

3. Dende o punto de vista da cronoloxía relativa das accións expresadas polas cláusulas constituíntes, coincidimos con Moreno Cabrera (1991: 667-673) en establecer dous tipos de relación lóxica entre os dous "eventos" contidos en cada unha destas oracións, que el denomina "adverbiales relacionales": as que expresan antecedencia (condicionais, causais, concesivas) e sucesión (finais, consecutivas) ${ }^{4}$.

3.1. Nas causais propiamente ditas, malia que a causa precede no tempo o efecto, no discurso é normal que se inverta esta orde lóxica, ben sexa por razóns estilísticas, ben por exixencia da conxunción ou, simplemente, porque cabe a dobre posibilidade:

(8a) Xoán madruga porque aproveita mellor o tempo

(8b) (precisamente) Porque 5 aproveita mellor o tempo, Xoán madruga

3 Outros gramáticos desta lingua, como R. Seco (1968: 223-226), Gili Gaya (1964: 312) ou Marcos Marín (1986: 396), agrupan as comparativas e consecutivas entre as "cuantitativas", e as condicionais e concesivas entre as "causativas". Marcos Marín engade, dentro destas últimas, as causais e finais e, por outra banda, sinala a relación entre consecutivas e condicionais, que é semellante á que existe entre causais e finais, pois ambas enfocan o mesmo fenómeno dende extremos opostos. Este mesmo autor, na gramática que publicou en colaboración con Satorre Grau / Viejo Sánchez (1998: 442 e ss.), segue incluíndo entre as proposicións subordinadas circunstanciais de causa, os cinco tipos sinalados e emparentados semanticamente (causais, finais, consecutivas, condicionais e concesivas).

Outros autores foron máis lonxe, e non só na agrupación destas oracións. Por exemplo, Isbä șescu Häulicä (1981) distingue dentro das paratácticas [= coordenadas ] dous tipos, determinados polos trazos [+ cuantitativo] e [+ causativo], respectivamente. Ó primeiro pertencen as copulativas, disxuntivas e conclusivas; ó segundo, as condicionais, concesivas e conclusivas. A novidade desta autora radica na inclusión das dúas primeiras deste segundo grupo entre as coordenadas, cando a maioría das gramáticas non dubidan en asignarlle o carácter hipotáctico ou subordinado.

4 Incrementa este segundo grupo coas aditivas (se un evento se dá ademais doutro) e as substitutivas (se se dá en vez doutro).

5 A maioría dos autores, aínda admitindo que as cláusulas con porque van en segundo lugar, recoñecen que non é imposible que esta conxunción apareza ó comezo da oración causal, sobre todo cando se usa enfaticamente ou con valor de réplica. Para unha información máis ampla, cfr., entre outros, M. Seco (1982: 123, nota), Santos Río (1982: 232-42), Narbona Jiménez (1990: 49-50), Alarcos (1994: 366) ou Mosteiro Louzao (1999: 111-17). 
Estas oracións constrúense xeralmente en indicativo ou infinitivo, pero emprégase o subxuntivo cando se nega a causa, que é correxida por unha adversativa:

(9) Non o fago porque esteas ti diante, senón porque me gusta,

onde a partícula negativa "alcanza", non o efecto, senón a relación de causalidade [= 'fágoo, non porque esteas..., senón...']. Se a causa estivese en indicativo, o elemento negado sería o expresado polo verbo que está precedido do adverbio non ${ }^{6}$.

3.2. Nas finais, a diferencia das anteriores, o efecto é anterior no tempo e, a partir del, empréganse os medios para acadar o obxectivo proposto. A relación semántica entre causa e finalidade é evidente, pois ambas consideran a mesma acción dende perspectivas opostas. Segundo Marcos Marín (1986: 388), trátase de aspectos complementarios dentro do fenómeno da causalidade.

Dende o punto de vista sintagmático, o normal é que a cláusula que expresa o fin ou o propósito con que se realiza unha acción vaia posposta, se ben a súa posición pode ser a inicial cando se tematiza o contido de finalidade:

(10a) Xoán madruga para aproveitar mellor o tempo

(10b) Para aproveitar mellor o tempo, Xoán madruga

Nestes exemplos emprégase o infinitivo simple (o composto é incompatible polo seu contido de anterioridade á outra acción) porque o suxeito das dúas cláusulas é o mesmo. Pero cando non son correferentes, a virtualidade exprésase por medio do modo subxuntivo?:

(10c) Xoán madruga para que o seu fillo aproveite mellor o tempo

(10d) Para que o seu fillo aproveite mellor o tempo, Xoán madruga

3.3. Nas cláusulas das consecutivas, ás veces o enunciado pola subordinante é motivo ou causa que xera o expresado pola subordinada. A profesora Fuentes (1985) pon de manifesto a relación entre estas oracións e as causais coas seguientes palabras:

“oración causal" y "oración consecutiva" son dos modos lingüísticos de expresar una misma relación lógica. Lo que varía es el orden lingüístico, no el lógico. Y esta distinción queda marcada también por la diferencia nexual. En la oración causal, el miembro que va marcado con el nexo es el del nudo primero del árbol, no el segundo como en la consecutiva (1985: 28).

6 Para as diferentes combinacións de negación e elemento afectado, pódese ver o noso traballo de próxima publicación Mosteiro Louzao (2000: $§ 3.2 .1$ ).

7 Esta é a norma, pero hai excepcións que non responden ás expectativas, dependendo basicamente da construcción do verbo da cláusula non final e do tipo de complementos que leve. Para máis información e exemplos concretos, poden verse os traballos de Galán Rodríguez (1992: 154-5 e 1999, III: 3634), así como o de García (1996: 74 e ss.). 
A estreita relación semántica que existe entre estas dúas clases de oracións advírtese en exemplos como os seguintes, en que as consecutivas teñen un significado equivalente ó das respectivas causais invertidas:

(11 a) Onte estivo enfermo, xa que logo non puido ir á escola

(11b) Onte non puido ir á escola porque estivo enfermo

(12c) O meu compañeiro estudiou tanto que rematou a carreira en dous anos

(12d) O meu compañeiro rematou a carreira en dous anos de tanto que estudiou

(12e) O meu compañeiro rematou a carreira en dous anos porque estudiou tanto

Diferéncianse dous tipos, segundo indiquen unha consecuencia posible dun feito expresado anteriormente (constrúense con logo, de modo que, polo tanto, xa que logo, conque, etc.... e habitualmente interprétanse como "inversión" dunha causal) ou unha consecuencia exixida pola intensificación do contido da primeira cláusula (co dobre nexo correlativo tan(to) / tal... que). Narbona distingue as consecutivas "de intensidade" das "de maneira", e mesmo sinala un terceiro subtipo, en que se funden ambas (cfr. Narbona 1978 e 1990: 76).

Atendendo ó seu funcionamento sintáctico, a maioría dos autores coinciden en incluíren as primeiras entre as coordenadas e as segundas nas subordinadas". A diferencia das causais e finais, estas oracións teñen unha distribución fixa, coa consecuencia sempre posposta, concordando desde xeito a orde gramatical coa lóxica e temporal:

(13a) Xoán madruga, logo (polo tanto) aproveita mellor o tempo

(13b) Xoán madruga tanto que aproveita mellor o tempo

(13c) (Desexo que/oxalá) teñas tanta sorte que che toque a lotería

(13d) Non hai libro tan malo que non teña algo bo

3.4. Cando a causa é hipotética, adopta a forma das condicionais. O contido da prótase ou condicionante actúa como suposta causa que motiva o enunciado na apódose ou consecuente. A posición da cláusula con se é variable e a combinación modo-temporal dos dous membros é moi ampla:

8 A esta afinidade de significado refírense case todos os estudios de sintaxe oracional. Polo que respecta ó galego, pode verse, por exemplo, a Gramática de Álvarez et alii (1986: 531).

9 A mencionada Fuentes (1985: 33-36) combina a consecuencia lóxica (“de dicto") e a real (“de re") cos tipos de condición de Van Dijk e establece tres grupos baseados na natureza lóxica da condición e a consecuencia, a que pertencen tanto as que levan intensificador como as que non:
(a) $\mathbf{A}$ [=causa] é condición necesaria de $\mathbf{B}$ [=consecuencia].
(b) $\mathbf{B}$ é consecuencia necesaria de $\mathbf{A}$.
(c) A é condición suficiente de $\mathbf{B}$ e $\mathbf{B}$ consecuencia posible de $\mathbf{A}$. 
(14a) Se madruga, Xoán aproveita mellor o tempo

(14b) Se madruga, ogallá Xoán aproveite mellor o tempo

(14c) Se madrugase, Xoán aproveitaría mellor o tempo

(14d) Se madrugase, quizais Xoán aproveitase mellor o tempo,

exemplos a que hai que engadir outros tantos procedentes de inverter a orde clausal $^{10}$.

As nocións de condición e causa e a súa relación suscitaron controversia en distintos autores, tal como pon de manifesto Ferrater Mora no seguinte fragmento:

uno de los problemas más persistentes suscitados por la noción de condición ha sido el de la relación que esta noción mantiene con la de causa. Algunos autores han indicado que se trata de dos nociones distintas: la causa tiene un sentido positivo, siendo aquello por lo cual es o sucede, mientras la condición tiene un sentido negativo, siendo aquello sin lo cual no sería o sucedería. Otros autores, en cambio, han estimado que no hay posibilidad de distinguir entre causa y condición. Más todavía: lo que llamamos causa es, a su entender, reducible a conjunto de condiciones (1971, s.v. condición).

A relación de causalidade entre consecutivas e condicionais (a que xa nos referimos de pasada na nota 2) foi sinalada por Polo no seu traballo sobre estas últimas oracións:

la consecutiva expresa causalidad entre dos sintagmas: hecho y consecuencia; la condicional lo hace a la inversa: condición y hecho; no es -la consecutiva- un 'hacia', sino un 'detrás' (1971: 11).

Hai estructuras formalmente condicionais que polo seu contido equivalen a oracións causais. Trátase de construccións en que o elemento que figura como prótase se refire a un feito cumprido e verificado, que na realidade é a causa do enunciado na apódose:

(15a) Se non foi quen de o conseguir con tantos medios ó seu favor, é mellor que o deixe

(15b) Se xa tiña recollida a herba, nada lle importaba que chovese

${ }^{10}$ Esta non é máis que unha breve mostra das múltiples posibilidades que se poden dar nas condicionais. Como aquí non se trata dun estudio completo e como, por outra banda, son moi abundantes os adicados a estas oracións, limitámonos a deixar constancia da súa posibilidade de se construíren tanto en indicativo como en subxuntivo.

Entreoutros, pode verse o traballo de Veiga (1991a), quen, desde unha perspectiva funcional, establece as oposicións gramaticais dos verbos integrantes das condicionais e concesivas en español. Para o galego é útil outro deste mesmo autor (cfr. Veiga 1991b) e os de Monteagudo Romero (1982 e 1989). así como a xa mencionada Gramática de Álvarez et alii (1986: 532-38). 
Se na primeira se constata que efectivamente "non foi quen de o conseguir" e na segunda que "xa tiña recollida a herba", ó se converteren en causais, resultarían:

(16a) É mellor que o deixe, xa que non foi quen de o conseguir con tantos medios ó seu favor

(16b) Nada lle importaba que chovese porque xa tiña recollida a herba

3.5. Nos dous membros das concesivas un supón un impedimento para o outro, pero non é causa ou motivo suficiente para evitar o seu cumprimento, a diferencia das condicionais ${ }^{11}$, nas que se expresa un feito que se non se cumpre será causa suficiente para anular o que se enuncia na oración nuclear (cfr. Alarcos et alii 1981: 122).

En certo modo cabe interpretar, como sostén Narbona, o término concesión como condición inoperante ou insuficiente. Este autor pon en relación así mesmo a concesividade coa causa, entendéndoa como "contra-causa" ou “non-causa” en canto que o 'efecto' ou 'resultado' é contrario -ou, alomenos, distinto- ó normalmente esperable (cfr. Narbona 1990: 107-108).

Esta aproximación entre os valores concesivo e causal foi apuntada tamén por Cano Aguilar (1992: 340-341) ó estudiar a construcción de como + subxuntivo

1 Os gramáticos adoitan sinalar a relación que existe entre concesivas, condicionais e adversativas. Neste senso poden servir como mostra as opinións de Gili Gaya e Rojo, por citar dous autores que clasifican e enfocan estas oracións desde perspectivas diferentes: "[la subordinada concesiva] es como una condición que se considera desdeñable e inoperante para la realización del hecho. Tienen, por lo tanto, semejanza de sentido con las condicionales; pero por otro lado están emparentadas lógica e históricamente con las adversativas, y la conjunción aunque se usa actualmente con los dos valores" (Gili Gaya 1964: 322); "las adversativas se relacionan con las concesivas y con las condicionales, lo cual redunda en el sentido de que deben ser consideradas oraciones bipolares y no oraciones policlausales. La conexión con las concesivas es natural, puesto que ambos tipos de oración expresan dos hechos que se contraponen [...]. Por su parte, las adversativas exclusivas están emparentadas históricamente con las expresiones condicionales con condicionante negativo (de si no a sino), con lo cual tenemos otro argumento a favor de la consideración de las adversativas como bipolares" (Rojo 1978: 110-111).

R. Seco, como xa vimos ó comezo, inclúe no grupo das oracións de causalidade as condicionais e concesivas, "toda vez que la condición es antecedente indispensable para un cierto efecto, y en lo concesivo hay un obstáculo previo, especie también de condición, aunque desdeñable" (1968: 226). Estas últimas palabras son as que emprega tamén Marcos Marín (1986: 416) para marcar a relación entre estas oracións, relación que é subliñada igualmente por Cortés Parazuelos (1993: 229), dentro do que esta autora denomina "estructura sintáctica bipolar".

Algúns dos aspectos que diferencian concesivas e condicionais, a partir da coincidenciatipolóxica dunhas e outras (coincidencia que é negada por Veiga 1991a: 311-312), poden verse en Rivas (1989: 241-242), quen estudia así mesmo as características comúns e os factores diferenciais de concesivas e adversativas. Os exemplos poderían seguir multiplicándose neste senso. Para rematar, deixamos constancia da aportación de Vera Luján (1981), para quen a adversación e a concesión constitúen subclases lóxicosemánticas que recobren esquemas estructurais diferentes. As adversativas, igual que na gramática tradicional, exprésanse por medio de esquemas coordenados, mentres que as concesivas o fan por medio da dobre vía da coordenación e a subordinación. 
[que habitualmente é condicional: como non veñas, voute buscar], sobre todo cando existe oposición 'negativo' / 'afirmativo' entre subordinada e nuclear ou principal: depende de se a primeira actúa como un motivo ou como un obstáculo do enunciado na segunda.

Rivarola, a partir do carácter presuposicional destas oracións, interpreta a relación concesiva como "una relación (lógicamente) conjuntiva entre dos frases que es contraria a una relación implicativa presupuesta entre una de ellas y la negación de la otra" (1976: 4-5). Máis abaixo define o enunciado concesivo como "contrario a una expectativa" (1976: 6). Así, nas oracións

(17a) Aínda que madruga, Xoán non aproveita mellor o tempo,

(17b) Xoán non aproveita mellor o tempo, aínda que madruga,

pode observarse que a expectativa ou relación implicativa presuposta "madrugar $\rightarrow$ aproveitar o tempo" non chega a cumprirse [= "non aproveita mellor o tempo polo feito de - a causa de- madrugar'] $]^{12}$.

Cando o impedimento é real, como ocorre nos dous exemplos anteriores, constrúense en indicativo, pero se é hipotético ou irreal, fano en subxuntivo:

(17c) Aínda que madrugue, Xoán non aproveita mellor o tempo

(17d) Xoán non aproveita mellor o tempo, aínda que madrugue

(17e) Aínda que madrugase, Xoán non aproveitaría mellor o tempo

(17f) Xoán non aproveitaría mellor o tempo, aínda que madrugase

(17g) Aínda que madrugase, quizais Xoán non aproveitase mellor o tempo

(17h) Quizais Xoán non aproveitase mellor o tempo, aínda que madrugase

4. Esta breve exposición permitiunos sinalar as liñas xerais de coincidencia e diverxencia que presentan as oracións do chamado "ciclo causal", que, segundo Román del Cerro,

se inicia con la afirmación de la relación causa/efecto en dos vías distintas, la eficiente y la hipotética, permitiendo ambas las dos inversiones posibles, la proyectiva y la funcional, para cerrarse con la negación de la causalidad (1984: 57) ${ }^{13}$.

12 Estas dúas últimas clases de oracións -condicionais e concesivas- deron orixe a unha rica e complicada tipoloxía (reais, non reais, potenciais, irreais, etc.), sobre todo a partir das relacións de modo e tempo que presentan os esquemas das súas cláusulas constituíntes. Poden verse, por exemplo. resumos e críticas sobre os criterios adoptados pola gramática tradicional e por outros autores sobre a súa clasificación, así como as súas propias propostas. en Rojo / Montero (1983: 11-40), Rivas (1990) ou Veiga (1991a: 7 e ss.).

13 Desenvolve cada unha destas estructuras nas pp. 55-92. Pode comprobarse tamén a relación que manteñen entre si consultando estes termos no glosario que Martínez (1994b) adica a compendiar os fundamentos da gramática funcional do español. 
Se tomamos como mostra un exemplo de cada clase das oracións anteriores, comprobamos que a relación eficiente de (8a) equivale á hipotética de (13a), que se converte na proxectiva de (12a) ou na funcional de (10a), cerrándose o ciclo coa negación da causalidade de (16a).

5. En todas estas oracións hai unha relación estreita entre os enunciados das dúas cláusulas constituíntes para expresar diferentes aspectos de causalidade, polo que propoñemos a denominación de lóxicas para todas elas, fronte ás non lóxicas ${ }^{14}$, en que a relación se establece entre unha das cláusulas presentes, xeralmente a encabezada polo nexo, e outra con verbo elíptico que xustifica o acto enunciativo e domina a que figura como efecto. Na seguinte serie de exemplos pertencentes a este segundo tipo pode comprobarse o que acabamos de expor:

(18a) Está enfermo, porque estivo tusindo toda a noite

(19a) Merquei un coche novo, para que o saibas

(20a) Ten a luz acendida, polo tanto non saíron da casa

(21a) É tan alto que deu un golpe na testa

(22a) Se preguntan por min, vou de viaxe

(23a) Aínda que lle vén mal ó campo, mañá choverá

En todos os casos, como a relación entre o expresado polas dúas cláusulas presentes no discurso difire da conexión real existente nas súas respectivas estructuras profundas, é necesario sobreentender un predicado do tipo que sinalamos a continuación entre colchetes, que é o que tomamos como referencia para marcar a relación lóxica co que figura na outra cláusula:

(18b) [DIGO que] está enfermo porque estivo tusindo toda a noite

(19b) [DÍGOCHE que] merquei un coche novo para que o saibas

(20b) Ten a luz acendida, polo tanto [DEDUZO / PENSO que] non saíron da casa

(21b) É tan alto que [NON COLLE POLA PORTA e, como consecuencia,] deu un golpe...

(22b) Se preguntan por min, [DILLES que] vou de viaxe

(23b) Aínda que che vén mal, [PENSO / DIGO que] mañá choverá

6. As páxinas que preceden constitúen só unha aproximación ás diferentes clases de oracións que poden encadrarse dentro do "ciclo causal" e teñen como finalidade pór en evidencia as súas similitudes e demostrar por que deben figurar baixo unha mesma etiqueta relacionada coa 'causa'. Un estudio completo esixe partir dun corpus moito máis amplo, con que se poida constatar o que de forma xeral

${ }^{14}$ Para esta clasificación aplicada ás causais, pode verse a parte final de Mosteiro Louzao (1998: 22632). 
expuxemos neste artigo, así como sinalar as posibles excepcións ó formulamento básico que nos permitiron facer os nosos exemplos. Destes, sen embargo, podemos sacar algunhas conclusións:

6.1. As cinco clases de oracións estudiadas teñen un significado común de 'causalidade', entendida esta nun senso amplo, cos matices propios que as diferencian.

6.2. A partir desta afinidade semántica, constatamos tamén algunhas analoxías sintácticas:

6.2.1. Dende o punto de vista temporal, as formas verbais das cláusulas introducidas polo nexo nas oracións causais, condicionais e concesivas necesariamente expresan unha acción anterior ou simultánea con relación á cláusula nuclear ou principal. Nas finais e consecutivas o proceso é inverso.

A partir dos exemplos propostos, pódense facer outras combinacións cos verbos das dúas cláusulas constituíntes e comprobar a súa verosimilitude. Deste xeito, non serían posibles construccións como as seguintes, pois a cronoloxía relativa entre as dúas accións mostra a súa incompatibilidade:

(23) * Xoán madrugou porque aproveitará mellor o tempo

(24) * Se Xoán madruga, aproveitou ...

(25) * Aínda que Xoán madrugará, non aproveitou ...

(26) * Xoán madruga para que ti aproveitases...

(27) * Xoán madruga, polo tanto aproveitou...

(28) * Xoán madruga tanto que aproveitou..., etc.

6.2.2. Polo que respecta ó modo, excepto as finais, que se constrúen en subxuntivo (ou en infinitivo), as demais pódeno facer en indicativo ou subxuntivo, predominando un ou outro segundo os casos.

6.2.3. A disposición das cláusulas no discurso é ríxida nas consecutivas, pois o consecuente loxicamente ten que ir detrás do antecedente; pero nas demais a orde sintagmática ofrece a dobre posibilidade de aparecer en primeiro ou segundo lugar, se ben a interpretación pragmática non é a mesma.

6.3. Sintáctica e semanticamente, podémolas clasificar como lóxicas ou non lóxicas, dependendo de se a relación de causalidade ten lugar entre as cláusulas presentes no discurso ou se é necesario recuperar algunha implícita. 


\section{Referencias bibliográficas}

Alarcos Llorach, E. (1994): Gramática de la lengua española (Madrid: Espasa-Calpe).

Alarcos Llorach, E. et alii (1981): Lengua española (Madrid: Santillana).

Álvarez, R., et alii (1986): Gramática galega (Vigo: Galaxia).

Campo Fernández, M M $^{\mathrm{a}}$. del (1998): Las construcciones causales en español (Oviedo: Universidad de Oviedo).

Cano Aguilar, R. (1992): "Nuevas precisiones sobre como + subjuntivo", Actas del II Congreso Internacional de Historia de la Lengua Española, I: 333-345 (Madrid: Pabellón de España).

Cortés Parazuelos, $M^{\mathrm{a}}$ H. (1993): “'Bipolares’ al servicio de la 'concesividad': causales, condicionales y adversativas", Verba, 20: 221-54.

Ferrater Mora, J. (19715): Diccionario de Filosofía, I (Buenos Aires: Edit. Sudamericana).

Fuentes Rodríguez, C. (1985): Sintaxis oracional (Las oraciones consecutivas en español) (Sevilla: Ediciones Alfar).

Galán Rodríguez, C. (1992): Las oraciones finales en español. Estudio sincrónico (Cáceres: Universidad de Extremadura).

Galán Rodríguez, C. (1999): “La subordinación causal y final”, en Bosque, I. I Demonte, V. (eds.) (1999): Gramática descriptiva de la lengua española, 3: 3597-3642 (Madrid: Espasa-Calpe).

Gili Gaya, S. (1964): Curso superior de sintaxis española (Barcelona: Vox, Bibliograf, S. A.).

Isbä şescu Häulicä, C. (1981): "Propuesta para una clasificación de las oraciones paratácticas en español", In honorem E. Coseriu, Logos Semantikos, IV (Gramática): 239-248 (Madrid: Gredos).

Marcos Marín, F. (1986²): Curso de gramática española (Madrid: Cincel).

Marcos Marín, F. et alii (1998): Gramática española (Madrid: Edit. Síntesis).

Martínez, J. A. (1994a): Cuestiones marginadas de gramática española (Madrid: Istmo).

Martínez, J. A. (1994b): Propuesta de gramática funcional (Madrid: Istmo).

Monteagudo Romero, H. (1982): Construccións condicionais no galego medieval, Memoria de licenciatura lida na Universidade de Santiago de Compostela (inédita).

Monteagudo Romero, H. (1989): "Subxuntivo futuro / indicativo presente na prótase das oracións condicionais do galego medieval", Actas do XIX ${ }^{\circ}$ Congreso Internacional de Lingiiística e Filoloxía Románicas (Santiago de Compostela, 1989). VI (1994): 337-352 (A Coruña: Fundación "Pedro Barrié de la Maza, Conde de Fenosa"). 
Moreno Cabrera, J. C. (1991): Curso universitario de lingüística general, I: Teoría de la gramática y sintaxis general (Madrid: Edit. Síntesis).

Mosteiro Louzao, M. (1998): "Clasificación de las oraciones causales: estudio crítico", Moenia. Revista de Lingüística \& Literatura Lucense, 3: 193-236.

Mosteiro Louzao, M. (1999): Las conjunciones de causa en castellano medieval: Origen, evolución y otros usos, Anexo 45 de Verba (Santiago: Universidade de Santiago de Compostela).

Mosteiro Louzao, M. (2000): Los esquemas causales en castellano medieval, Anexos Moenia (Santiago: Universidade de Santiago de Compostela) (en prensa).

Narbona Jiménez, A. (1978): Las proposiciones consecutivas en español medieval (Granada: Universidad de Granada)

Narbona Jiménez, A. (1990): Las subordinadas adverbiales impropias en español (II) (Causales y finales, comparativas y consecutivas, condicionales y concesivas) (Málaga: Librería Ágora).

Polo, J. (1971): Las oraciones condicionales en español (Ensayo de teoría gramatical) (Granada: Universidad de Granada / C.S.I.C.).

Rivarola, J. L. (1976): Las conjunciones concesivas en español medieval y clásico. Contribución a la sintaxis histórica española (Tübingen: Max Niemeyer / Verlag).

Rivas, E. (1989): “Observaciones sobre las concesivas. Su comparación con las condicionales y las adversativas", Verba, 16: 237-55.

Rivas, E. (1990): “A propósito de condicionales y concesivas reales. Referencias diacrónicas en torno a estas últimas”, Verba, 17: 159-169.

Rojo, G. (1978): Cláusulas y oraciones, Anexo 14 de Verba (Santiago: Universidade de Santiago de Compostela).

Rojo, G. / Montero Cartelle, E (1983): La evolución de los esquemas condicionales (potenciales e irreales desde el Poema del Cid hasta 1400), Anexo 22 de Verba (Santiago: Universidade de Santiago de Compostela).

Román del Cerro, J. L. (1984): Teoría del nexo: la estructura léxico-semántica de la nexuación interoracional (Alicante: Publicaciones de la Universidad de Alicante).

Sánchez Márquez, M. J. (1982²): Gramática moderna del español. Teoría y norma (Buenos Aires: Ediar).

Santos Río, L. (1982): "Reflexiones sobre la expresión de la causa en español”, Studia Philologica Salmanticensia, 6: 231-77.

Seco, M. (1982): Gramática esencial del español (Madrid: Aguilar).

Seco, R. (1968): Manual de gramática española (revisado y ampliado por M. Seco) (Madrid: Aguilar).

Tekavčic, P. (1972): Grammatica storica dell'italiano. II: Morfosintassi (Bologna: Societá Editrice Il Molino). 
Tesnière, L. (1982²): Éléments de Syntaxe Structurale (Paris: Klincksieck) [vers. esp., en 2 T, de E. Diamante (1994) (Madrid, Gredos)].

Veiga, A. (1991a): Condicionales, concesivas y modo verbal en español (Santiago: Universidade de Santiago de Compostela).

Veiga, A. (1991b): "Sobre a decadencia do subxuntivo en prótases condicionais en galego e español e a subxuntivación da forma cantara", en Brea, M. / Fernández Rei, F (eds.): Homenaxe ó profesor Constantino García. I: $497-539$ (Santiago: Universidade de Santiago de Compostela).

Vera Luján, A. (1981): "En torno a las oraciones concesivas: concesión, coordinación y subordinación", Verba, 8: 187-203. 